\title{
Exploring symptoms of somatization in chronic widespread pain: latent class analysis and the role of personality
}

This article was published in the following Dove Press journal:

Journal of Pain Research

24 July 2017

Number of times this article has been viewed

\begin{abstract}
Andrea Burri ${ }^{1,2}$
Peter Hilpert ${ }^{3}$

Peter McNairl

Frances MWilliams ${ }^{4}$

'Health and Rehabilitation Research Institute, School of Clinical Sciences, Faculty of Health and Environmental Sciences, Auckland University of Technology, ${ }^{2}$ Waitemata Pain Service, Department of Anaesthesiology and Perioperative Medicine, North Shore Hospital, Auckland, New Zealand; ${ }^{3}$ Department of Psychiatry and Behavioral Sciences, University of Washington, Seattle, WA, USA;

${ }^{4}$ Department of Twin Research and Genetic Epidemiology, King's College London, London, UK
\end{abstract}

\begin{abstract}
Chronic widespread musculoskeletal pain (CWP) is a condition manifesting varied co-symptomatology and considerable heterogeneity in symptom profiles. This poses an obstacle for disease definition and effective treatment. Latent class analysis (LCA) provides an opportunity to find subtypes of cases in multivariate data. In this study, LCA was used to investigate whether and how individuals with CWP could be classified according to 12 additional somatic symptoms (migraine headaches, insomnia, stiffness, etc.). In a second step, the role of psychological and coping factors for the severity of these co-symptoms was investigated. Data were available for a total of $\mathrm{N}=3,057$ individuals (mean age $=56.6$ years), with $15.4 \%$ suffering from CWP. In the latter group, LCA resulted in a three-class solution $\left(\mathrm{n}_{\text {group } 1}=123 ; \mathrm{n}_{\text {group } 2}=306 ; \mathrm{n}_{\text {group } 3}=43\right)$ with groups differing in a graded fashion (i.e., severity) rather than qualitatively for somatic co-symptom endorsements. A consistent picture emerged, with individuals in the first group reporting the lowest scores and individuals in group 3 reporting the highest. Additionally, more co-symptomatology was associated with higher rates of anxiety sensitivity and depression, as well as more extraversion and emotional instability. No group differences for any of the coping strategies could be identified. The findings suggest that CWP has several detectable subtypes with distinct psychological correlates. The identification of CWP subgroups is important for understanding disease mechanisms and refining prognosis as well as stratifying patients in clinical trials and targeting specific treatment at the subgroups most likely to respond.
\end{abstract}

Keywords: anxiety sensitivity, extraversion, depression, emotional stability, somatoform symptoms

\section{Introduction}

Chronic widespread musculoskeletal pain (CWP) is the core symptom of fibromyalgia (FM) affecting up to $18 \%$ of the general population and representing an important measure of the global burden of pain. ${ }^{1,2} \mathrm{CWP}$ has been given a standard definition by the American College of Rheumatology, emphasizing axial pain as a constant feature and the presence of pain in the left and right sides of the body, above and below the waist. ${ }^{3}$ CWP is more prevalent in females than in males. ${ }^{4,5}$ The condition has been related to a number of psychological and medical conditions and complaints, such as depression, anxiety, fatigue, distress, and other somatic symptoms. ${ }^{6,7}$ The processes underlying the development, prognosis, and treatment of CWP are of a complex nature. Findings from the numerous studies on CWP indicate that factors other than biomechanical or neurophysiologic ones may have much greater impact on the condition and the disease can therefore be best explained by a biopsychosocial model. ${ }^{8-10}$ Therefore, recently, the exploration of psychological entities and cognitive behavioral factors has
Health and Rehabilitation Research Institute, School of Clinical Sciences, Faculty of Health and Environmental Sciences, Auckland University of Technology, North Shore Campus, 90 Akoranga Drive, Northcote North Shore, Auckland 0627, New Zealand

Tel +64 21 99996120

Email andrea.burri@aut.ac.nz 
been given more attention and the importance of personality traits and illness coping (i.e., referring to the emotional and behavioral response strategies, such as avoidance or magnification) has repeatedly been demonstrated. ${ }^{11-14}$

The prognosis for many chronic pain conditions such as CWP has been found to be influenced by psychological factors such as anxiety or depression. Especially, the relationship between depression and chronic pain has been subject to extensive research, and studies have consistently found an association between depressive symptoms and higher levels of pain intensity, more functional limitation and disability, and worse prognosis. ${ }^{7,15}$ Furthermore, a link between anxiety sensitivity (AS) - describing the fear of anxiety sensations and their believed negative consequences - in the maintenance of chronic pain and disability has been reported. ${ }^{16}$ Similarly, the importance of personality as part of the biopsychosocial disease approach has been established in numerous studies. Personality traits seem to influence an individual's reaction and coping with CWP, with the fundamental personality trait of neuroticism (i.e., referring to the relatively stable tendencies to respond with negative emotions to threat, frustration, or loss) being especially relevant. ${ }^{17}$ Apart from these psychological factors, cognitive-behavioral variables such as individual coping have also been implicated in CWP. Studies investigating the importance of individual coping have identified a set of adaptive and maladaptive coping strategies associated with adjustment in chronic pain, suggesting them to represent premorbid risk or protective factors for the development and/ or maintenance of CWP. ${ }^{14}$ In this context, coping refers to the emotional and behavioral response strategies to problems/ stressors, such as avoidance or magnification. Acknowledgment of these psycho-affective factors in pain chronification seems important also in relation to the theory of "central sensitization". Central sensitization describes an increase in the excitability and synaptic efficacy of neurons in central nociceptive pathways, manifesting itself in hypersensitivity, allodynia, and hyperalgesia. Besides specific neurophysiological changes to the nervous system, neuroplastic alterations in nociceptive sensitivity are also more likely to occur due to psychological and environmental predisposing factors (such as preexisting anxiety about pain). ${ }^{18,19}$

CWP, together with FM, is also a condition of varied co-symptomatology and shows considerable heterogeneity in symptom profiles. ${ }^{20-24}$ The multidimensional nature of the condition fuels the debate over disease definition and poses an obstacle for efficient and effective research, partly due to the lack of specific disease markers. It further hinders more in-depth exploration of the interactions among its clinical features and their association with treatment outcomes. While CWP and its associated comorbidities have been fairly well studied, the empirical symptomatic heterogeneity of CWP and how it potentially relates to personality and disease coping has been neglected so far. Hence, little is known about the etiology of co-symptoms, and this hampers the understanding of underlying mechanisms that drive the condition. Identification of CWP subgroups in terms of co-symptomatology severity and how this may relate to psycho-behavioral factors, however, is necessary not only for the successful outcomes of future biomedical research that may depend upon the accuracy of phenotype description but also has equally important clinical implications - both on prevention and on management of the condition.

The first aim of this study was to compare levels of cosymptoms in individuals with and without CWP. We then used latent class analyses (LCAs) to investigate whether individuals with CWP can be classified according to their additional somatic symptoms. Finally, the role of psycho-affective factors and coping behavior for the extent and severity of these co-symptoms was compared between the CWP subgroups.

\section{Participants and methods Study population}

The study sample consisted of unselected Caucasian female monozygotic (MZ) and dizygotic (DZ) twins from the TwinsUK Registry. ${ }^{25}$ A large number of previous studies, including questionnaires and extensive clinical investigations, have shown twins to be comparable with age-matched singletons for a variety of disorders and lifestyle factors. ${ }^{26}$ For more information on the TwinsUK cohort. ${ }^{27}$ For this study, data collection by self-report questionnaire for the various traits was performed between 2008 and 2013. Excluded from the study were twins having known causes of pain such as fracture, cancer, and rheumatoid arthritis. Data on CWP status were available for a total of $\mathrm{N}=3,057$ individuals $\left(\mathrm{M}_{\text {age }}=\right.$ 56.6 years, standard deviation $[\mathrm{SD}]=13.8)$, with $472(15.4 \%)$ who fulfilled criteria for CWP (see Assessment instruments section). Only one twin per family (random selection) was included in the analyses. Ethical approval was obtained by the St Thomas' Hospital Research Ethics Committee. All twins provided written consent and were unaware of the research hypotheses addressed in this study. The research followed the tenets of the Declaration of Helsinki.

\section{Assessment instruments}

Sociodemographic characteristics of the participants were available from the TwinsUK database. Information on 12 
somatic co-symptoms including fatigue, migraine, heartburn, headache, backache, insomnia, stiffness, palpitations, joint pain, dizziness, shaking, and hot and cold spells was collected using a study-specific list that had to be responded on a Likert-type scale ranging from "Never" (0) to "Often" (4) (question asked: "how often have you suffered from any of the following complaints in the last 3 months").

Chronic widespread pain was screened for using the four items pertaining to the "pain subscale" from the London Fibromyalgia Epidemiology Symptom Screening questionnaire (LFESSQ). ${ }^{28}$ The four items ask about pain in the left and right of the body and above and below the diaphragm lasting at least 7 days in the previous 3 months. To be classified as having CWP, participants had to respond "yes" to all four pain items with either both a right- and a left-side positive response or a positive response for pain at both sides. The utility of this phenotype assessment has repeatedly been demonstrated. ${ }^{20,29}$

Information on the Big Five personality dimensions was collected using the "Ten-Item Personality Index" (TIPI), an inventory designed to assess the different personality dimensions with optimized validity. ${ }^{30}$ The instrument measures very broad domains with only two items per dimension and uses items at both the positive and negative poles. Hence, the use of the TIPI is mainly indicated for situations where short measures are needed and personality is not the primary topic of interest. Response options are on a 7-point Likert scale ranging from "Disagree strongly" (1) to "Agree strongly" (7). Dimension scores are created by summing up the two item values for the different dimensions. Items 2, 4, 6, 8, and 10 are reversely scored. Cronbach's $\alpha$ in this study ranged from 0.43 to 0.69 .

To assess coping responses, the widely applied COPE self-report questionnaire was used. ${ }^{31}$ The COPE is a 60 -item measure that yields 15 factors (including positive reinterpretation and growth, mental disengagement, focus on and venting of emotions, use of instrumental social support, active coping, denial, religious coping, humor, behavioral disengagement, restraint, use of emotional social support, substance use, acceptance, suppression of competing activities, and planning) to assess active vs. avoidant coping strategies. ${ }^{25}$ Ratings are made on a 4-point Likert-type scale, ranging from "I usually don't do this at all" (1) to "I usually do this a lot" (4). The questionnaire shows acceptable psychometric properties with Cronbach's $\alpha$ ranging from 0.37 to 0.93 , test-retest reliabilities ranging from 0.46 to 0.86 and strong evidence of discriminant and convergent validity, with constructs such as hardiness, optimism, control, and self-esteem. For this study, Cronbach's $a$ ranged from 0.43 to 0.89 , in accordance with results from other studies.

AS was assessed using the 16-item Anxiety Sensitivity Index (ASI). ${ }^{32} \mathrm{AS}$ is defined as the fear of arousal-related sensations (e.g., fear of heart palpitations) arising from beliefs that these anxiety-related sensations have harmful consequences. Items are responded on a 5-point Likert-type scale ranging from "Very little" (0) to "Very much" (4). The psychometric properties and predictive validity of the widely used instrument have been well established, and a number of studies have provided evidence that the ASI has excellent internal consistency ( $\alpha=0.81-0.94$ ), a good degree of test-retest reliability ( $r=0.71-0.75)$, and a high degree of inter-item relatedness. Cronbach's $\alpha$ in this study was 0.92 .

Information on depression was obtained from the Composite International Diagnostic Interview (CIDI) questionnaire according to the Diagnostic and Statistical Manual of Mental Disorders, fourth edition (DSM-IV) criteria for major depression disorder (MDD). ${ }^{33}$ The CIDI was developed by the World Health Organization (WHO), and a number of studies have demonstrated the psychometric properties of the instrument, especially also in terms of the validity of its diagnostic assessment against a trained clinical interviewer. ${ }^{33}$

\section{Statistical analyses}

The goals of this study were threefold: 1) comparing symptoms between individuals with and without CWP; 2) identifying subgroups for individuals with CWP; and 3) examining if individuals in these subgroups differ in personality traits, AS, depression, and coping behavior. With respect to the first goal, because some of the variables and scales showed skewness, Mann-Whitney-Wilcoxon tests (nonparametric test, equivalent to $t$-test) were used to examine whether somatic co-symptoms were higher for individuals with CWP compared to individuals without CWP. In addition to $p$-values, effect sizes are reported as we expected even small differences to show statistical significance due to the large sample size. In this study, effect sizes of $d=0.2$ were considered as small.

We used LCA to detect subgroups of individuals with CWP scoring differentially on the somatic co-symptomatology. LCA is a structural equation modeling method allowing to find hidden groups (i.e., latent classes) of individual with similar somatic patterns. This approach allowed us to identify specific patterns of associations between the symptoms; e.g., some individuals with CWP might score high in symptoms $\mathrm{a}-\mathrm{c}$ but low in symptoms $\mathrm{d}-\mathrm{f}$, whereas other individuals might be characterized differently. Thus, the LCA enables us 
to find subgroups with no a priori definition. To identify the optimal number of classes, we used a stepwise approach and relied on the Vuong-Lo-Mendell-Rubin (VLMR) fit indices. We began with a model based on one class, then allowed the model to compute further classes one at the time, which is done until the VLMR fit indices become significant, consequently indicating that the model contains one class more than the optimal number of classes. To achieve the third goal, to identify differences in somatic co-symptoms, personality traits, AS, depression, and coping behavior across groups, a Kruskal-Wallis test was performed (nonparametric equivalent to analysis of variance [ANOVA]). Where significant, Wilcoxon tests were used to identify which specific group differed significantly from the others.

Data handling and descriptive analyses were carried out using STATA software (StataCorp. 2007, Stata Statistical Software: Release 10; StataCorp LP, College Station, TX, USA). MPlus 7.3 was used to examine the latent profile analysis. ${ }^{34} \mathrm{R}$ was used for the computation of Kruskal-Wallis and Wilcoxon tests. ${ }^{35}$

\section{Results}

\section{Sample characteristics comparison of individuals with and without CWP}

Table 1 shows the sample characteristics of the study variables in the CWP and the non-CWP groups. In terms of co-symptoms, the CWP group consistently reported higher scores across all symptoms $(d=-0.25$ to -1.37$)$ apart from migraine $(p=0.31)$ and dizziness $(p=0.48)$. In the CWP group, the most severe complaint was joint pain, whereas it was heartburn for the non-CWP group (Table 1). With regard to personality, the CWP group showed higher values in emotional instability compared to individuals without CWP. The two groups further differed in the coping strategies restraint and emotional support, as can be seen in Table 1.

\section{LCA}

LCA resulted in a three-class solution (VLMR fit indices $p$-values: Class $_{1}=0.000 ;$ Class $_{2}=0.000 ;$ Class $_{3}=0.000$; Class $_{4}=0.554 ; \mathrm{n}_{\text {group } 1}=123 ; \mathrm{n}_{\text {group } 2}=306 ; \mathrm{n}_{\text {group3 }}=43$ ) with the resulting groups differing in a graded fashion (severity) rather than qualitatively for somatic co-symptom endorsements (Table 2). A consistent picture emerged, in that individuals in the first group reported the lowest scores across all somatic co-symptoms apart from headache, whereas individuals in group 3 reported the highest scores across eight of the 12 symptoms. Individuals assigned to the second and third groups tended to report more heartburn, low back pain, insomnia, joint stiffness, joint pain, dizziness, and hot and cold spells compared to individuals in group 1. Similarly, individuals in group 3 reported greater severity across all symptoms apart from stiffness, back ache, and joint pain compared to groups 1 and 2 .

\section{CWP group comparison in terms of personality and coping strategies}

With regard to personality traits, the three CWP classes differed significantly in extraversion and emotional instability, with group 3 (i.e., highest co-symptomatology) being more extravert than groups 1 and 2 and similarly also reporting more emotional instability than individuals in groups 1 and 2 (Table 3 ). The three groups further differed in AS and depression, with group 3 scoring highest in both variables compared to groups 1 and 2 . No differences in any of the coping strategies could be found between the three CWP groups (Table 3).

\section{Discussion}

Individuals with CWP generally report a high rate of comorbid symptoms and disorders; therefore, it is not surprising that in this study, women with CWP also reported significantly more somatic co-symptoms compared to their non-CWP counterparts. We extended previous work by identifying subgroups that differ in the extent to which they report additional symptoms. Here, the most remarkable finding is that individuals with CWP can be categorized into three statistically distinct classes depending primarily on the number and severity of their somatic co-symptomatology. CWP group 1 reported the least somatic symptoms - apart from non-migrainous headache - compared to groups 2 and 3 . Even in comparison to group 2, the levels of non-migrainous headache reported by group 1 were not significantly higher. These low levels of somatic co-symptoms suggest that CWP group 1 is less likely to be "somatizers" and are predominantly affected by widespread musculoskeletal pain only, without additional symptoms.

Overall, group 3 had the highest scores across eight of the 11 symptoms and therefore represents a more "somatizing" CWP group. Interestingly, while group 3 reported more symptoms compared to groups 1 and 2, individuals in group 2 seemed to differ in a qualitative manner from groups 1 and 3 , by reporting more axial and peripheral joint symptoms including joint ache, low back pain, and stiffness than the others. This group seems to be particularly distinct from 
Table I Variable characteristics of individuals without CWP and with CWP

\begin{tabular}{|c|c|c|c|c|c|c|}
\hline \multirow[t]{2}{*}{ Variable } & \multicolumn{2}{|c|}{ Non-CWP (n = 2,585) } & \multicolumn{2}{|c|}{ CWP (n = 472) } & \multirow[t]{2}{*}{$\mathbf{p}$} & \multirow[t]{2}{*}{ d } \\
\hline & $\mathbf{M}$ & SD & $\mathbf{M}$ & SD & & \\
\hline$\overline{\text { Age }}$ & 55.30 & 14.2 & 62.27 & 10.87 & $<0.001$ & -0.55 \\
\hline Any medical condition & 0.11 & 0.31 & 0.32 & 0.47 & $<0.001$ & -0.53 \\
\hline AS & 13.30 & 9.21 & 15.94 & 9.98 & $<0.001$ & -0.27 \\
\hline Depression & 0.27 & 0.45 & 0.46 & 0.50 & $<0.001$ & -0.39 \\
\hline \multicolumn{7}{|l|}{ Symptoms } \\
\hline Fatigue & 1.22 & 1.24 & 2.11 & $\mathrm{I} .45$ & $<0.001$ & -0.66 \\
\hline Migraine & 0.19 & 0.39 & 0.32 & 0.47 & 0.314 & - \\
\hline Heartburn & 1.36 & 0.48 & 1.59 & 0.49 & $<0.001$ & -0.47 \\
\hline Headache & 0.86 & 1.02 & 1.13 & 1.16 & $<0.001$ & -0.25 \\
\hline Backache & 0.77 & 1.10 & 2.10 & 1.52 & $<0.001$ & -1.00 \\
\hline Insomnia & 0.97 & 1.23 & 1.63 & $\mathrm{I} .42$ & $<0.001$ & -0.50 \\
\hline Stiffness & 0.81 & 1.23 & 2.53 & 1.53 & $<0.001$ & -1.24 \\
\hline Palpitation & 0.31 & 0.75 & 0.71 & I.II & $<0.001$ & -0.42 \\
\hline Joint pain & 0.97 & 1.30 & 2.84 & $\mathrm{I} .43$ & $<0.001$ & -1.37 \\
\hline Dizziness & 0.22 & 0.60 & 0.52 & 0.90 & 0.478 & - \\
\hline Shaking & 0.17 & 0.55 & 0.42 & 0.90 & $<0.001$ & -0.34 \\
\hline Hot-cold spells & 0.66 & 1.20 & I.II & $\mathrm{I} .44$ & $<0.001$ & -0.34 \\
\hline \multicolumn{7}{|l|}{ Personality } \\
\hline Extraversion & 3.58 & 1.56 & 3.86 & 1.58 & $<0.001$ & -0.18 \\
\hline Agreeableness & 2.40 & 1.09 & 2.39 & 1.10 & $<0.001$ & 0.00 \\
\hline Emotional instability & 3.14 & 1.37 & 3.50 & 1.40 & $<0.001$ & -0.26 \\
\hline Conscientiousness & 1.95 & 0.92 & 1.99 & 1.00 & $<0.001$ & -0.04 \\
\hline Openness to new experiences & 3.19 & 1.25 & 3.20 & 1.23 & $<0.001$ & -0.00 \\
\hline \multicolumn{7}{|l|}{ Coping strategies } \\
\hline Emotional support & 5.50 & 1.65 & 5.16 & 1.57 & $<0.001$ & 0.21 \\
\hline Behavioral disengagement & 2.87 & 1.20 & 3.00 & I.2I & $<0.001$ & -0.11 \\
\hline Active coping & 6.09 & 1.39 & 5.95 & 1.42 & $<0.001$ & 0.10 \\
\hline Self-distraction & 4.91 & 1.50 & 5.13 & $\mathrm{I} .43$ & $<0.001$ & -0.15 \\
\hline Focus and venting of emotions & 4.34 & $\mathrm{I} .43$ & 4.34 & 1.46 & $<0.001$ & 0.00 \\
\hline Instrumental social support & 5.46 & 1.59 & 5.17 & 1.54 & $<0.001$ & 0.19 \\
\hline Positive reinforcement & 5.53 & $\mathrm{I} .45$ & 5.53 & 1.49 & $<0.001$ & 0.00 \\
\hline Restraint & 4.60 & 1.61 & 4.93 & 1.67 & $<0.001$ & -0.20 \\
\hline Planning & 6.13 & 1.39 & 6.10 & 1.42 & $<0.001$ & 0.02 \\
\hline Humor & 4.06 & 1.66 & 4.23 & 1.69 & $<0.001$ & -0.10 \\
\hline Acceptance & 6.01 & 1.39 & 6.03 & 1.40 & $<0.001$ & -0.01 \\
\hline Religious coping & 3.75 & 2.08 & 3.76 & 2.05 & $<0.001$ & -0.00 \\
\hline Denial & 2.99 & 1.25 & 3.12 & 1.28 & $<0.001$ & 0.10 \\
\hline Substance Use & 2.68 & 1.26 & 2.72 & 1.42 & $<0.001$ & 0.03 \\
\hline
\end{tabular}

Abbreviations: CWP, chronic widespread musculoskeletal pain; M, mean; SD, standard deviation; AS, anxiety sensitivity.

the others by the qualitative nature of their most commonly reported co-symptoms. Our findings are comparable to Vincent et al's reports, where cluster analyses on 581 women with FM resulted in four distinguishable groups, differing mainly by symptom severity levels (i.e., high to low average levels). The two subgroups with moderate symptom severity differed mainly in profiles of anxiety and depression. ${ }^{24}$

Comparing the three groups resulting from the LCA in terms of a number of psychological and behavioral correlates showed that the degree of subclinical psychological comorbidity (major depression and anxiety) varied across the groups. Individuals in group 3 with more somatic symptoms were also more likely to report higher levels of depression and more AS compared to the other two groups. More than 40 studies have explored the link between AS and chronic pain and have suggested AS to be an important contributing variable in the development and maintenance of pain. ${ }^{36,37}$ Individuals with elevated AS appear more likely to interpret somatic symptoms as aversive or dangerous, fostering catastrophic beliefs about pain that increase fear and avoidance may lead to poor response to some treatment modalities. A similar picture emerges for individuals prone to somatization. 
Table 2 Results of ANOVA (Kruskal-Wallis test) for the means of the II co-symptoms across the three CWP groups as identified by the LCA

\begin{tabular}{|c|c|c|c|c|c|c|c|c|}
\hline & \multicolumn{2}{|c|}{ CWPI $(n=123)$} & \multicolumn{2}{|c|}{ CWP2 $(n=306)$} & \multicolumn{2}{|c|}{ CWP3 $(n=43)$} & \multirow[t]{2}{*}{$\chi^{2}$} & \multirow[t]{2}{*}{ Contrasts } \\
\hline & $M$ & SD & $M$ & SD & $M$ & SD & & \\
\hline Fatigue & 1.50 & 1.32 & 2.41 & 1.50 & 2.57 & 1.27 & 4.7 & - \\
\hline Migraine & 0.28 & 0.45 & 0.33 & 0.47 & 0.35 & 0.49 & 0.6 & - \\
\hline Heartburn & 1.46 & 0.50 & $\mathrm{I} .64$ & 0.48 & 1.69 & 0.47 & 12.2 & $|<2|<3$, \\
\hline Headache & 1.07 & 1.19 & 1.04 & 1.07 & 1.78 & 1.35 & $1 \mathrm{I} .4$ & $\mathrm{I}<3,2<3$ \\
\hline Backache & 1.24 & 1.31 & 2.51 & 1.45 & 2.44 & 1.45 & 57.1 & $|<2|<3$, \\
\hline Insomnia & 1.05 & 1.25 & 1.82 & $\mathrm{I} .4 \mathrm{I}$ & 2.35 & 1.33 & 34.6 & $\mathrm{I}<2, \mathrm{I}<3,2<3$ \\
\hline Stiffness & 0.59 & 0.72 & 3.49 & 0.68 & 3.07 & 1.20 & 255.7 & $\mathrm{I}<2, \mathrm{I}<3,2<3$ \\
\hline Palpitation & 0.54 & 1.00 & 0.68 & 1.06 & 1.33 & 1.39 & 14.8 & $\mathrm{I}<3,2<3$ \\
\hline Joint pain & 1.44 & 1.39 & 3.52 & 0.84 & 3.28 & 1.08 & 152.8 & $\mathrm{I}<2, \mathrm{I}<3$ \\
\hline Dizziness & 0.35 & 0.74 & 0.45 & 0.82 & 1.36 & 1.23 & 39.9 & $\mathrm{I}<3,2<3$ \\
\hline Shaking & 0.10 & 0.33 & 0.17 & 0.37 & 2.69 & 0.78 & 205.8 & $\mathrm{I}<3,2<3$ \\
\hline Hot-cold spells & 0.75 & 1.21 & 1.14 & 1.45 & 2.02 & 1.61 & 22.0 & $\mathrm{I}<2, \mathrm{I}<3,2<3$ \\
\hline
\end{tabular}

Abbreviations: ANOVA, analysis of variance; CWP, chronic widespread musculoskeletal pain; LCA, latent class analysis; M, Mean; SD, standard deviation.

Table 3 Comparison of the psychological comorbidities, personality factors, and behavioral coping strategies across the three CWP groups

\begin{tabular}{|c|c|c|c|c|c|c|c|c|}
\hline & \multicolumn{2}{|c|}{ CWPI (n= I23) } & \multicolumn{2}{|c|}{ CWP2 $(n=306)$} & \multicolumn{2}{|c|}{ CWP3 (n = 43) } & \multirow[t]{2}{*}{$\chi^{2}$} & \multirow[t]{2}{*}{ Contrasts } \\
\hline & $\bar{M}$ & SD & $\bar{M}$ & SD & $\bar{M}$ & SD & & \\
\hline Age & 59.57 & 11.87 & 63.27 & 10.52 & 62.85 & 9.08 & 9.2 & $\mathrm{I}<2$ \\
\hline Medical condition & 0.27 & 0.45 & 0.32 & 0.47 & 0.43 & 0.51 & 1.2 & - \\
\hline AS & 13.99 & 8.30 & 15.80 & 10.14 & 21.91 & 10.92 & 12.7 & $\mid<3,2<3$ \\
\hline Depression & 0.35 & 0.48 & 0.47 & 0.50 & 0.70 & 0.47 & 11.4 & $\mid<3,2<3$ \\
\hline \multicolumn{9}{|l|}{ Personality } \\
\hline Extraversion & 4.13 & 1.55 & 3.68 & 1.61 & 4.34 & 1.27 & 8.9 & $1>2,2<3$ \\
\hline Agreeableness & 2.49 & 1.21 & 2.36 & 1.08 & 2.32 & 0.91 & 0.6 & - \\
\hline Emotional instability & 3.29 & $1.4 \mathrm{I}$ & 3.51 & 1.39 & 4.08 & 1.26 & 7.5 & $1<3,2<3$ \\
\hline Conscientiousness & 1.90 & 1.03 & 2.03 & 0.96 & 2.00 & 1.18 & 2.6 & - \\
\hline Openness to new experiences & 3.16 & 1.13 & 3.19 & 1.30 & 3.44 & 1.05 & 1.5 & - \\
\hline \multicolumn{9}{|l|}{ Coping strategies } \\
\hline Emotional support & 5.11 & 1.48 & 5.12 & 1.62 & 5.55 & 1.55 & 2.5 & - \\
\hline Behavioral disengagement & 3.08 & 1.24 & 2.92 & 1.15 & 3.27 & $\mathrm{I} .48$ & 2.7 & - \\
\hline Active coping & 5.92 & 1.32 & 5.99 & 1.46 & 5.73 & 1.47 & I.I & - \\
\hline Self-distraction & 4.97 & 1.38 & 5.14 & $\mathrm{I} .44$ & 5.47 & 1.48 & 3.4 & - \\
\hline Focus and venting of emotions & 4.41 & $\mathrm{I} .43$ & 4.35 & 1.47 & 4.08 & $\mathrm{I} .44$ & 1.3 & - \\
\hline Instrumental social support & 5.18 & 1.50 & 5.18 & 1.57 & 5.10 & $\mathrm{I} .48$ & 0.1 & - \\
\hline Positive reinforcement & 5.33 & 1.39 & 5,54 & 1.49 & 5.97 & 1.70 & 5.8 & - \\
\hline Restraint & 4.90 & 1.55 & 4.91 & 1.74 & 5.17 & 1.53 & 1.5 & - \\
\hline Planning & 5.99 & 1.34 & 6.17 & 1.43 & 6.00 & 1.55 & 1.9 & - \\
\hline Humor & 4.07 & 1.55 & 4.30 & 1.72 & 4.25 & 1.84 & 0.6 & - \\
\hline Acceptance & 5.85 & 1.36 & 6.12 & 1.43 & 6.03 & 1.33 & 3.2 & - \\
\hline Religious coping & 3.68 & 1.91 & 3.85 & 2.16 & 3.40 & $1.7 \mid$ & 0.8 & - \\
\hline Denial & 3.00 & 1.21 & 3.14 & 1.27 & 3.35 & 1.49 & 1.9 & - \\
\hline Substance use & 2.70 & 1.25 & 2.69 & 2.43 & 3.00 & 1.72 & 1.5 & - \\
\hline
\end{tabular}

Abbreviations: CWP, chronic widespread musculoskeletal pain; M, mean; SD, standard deviation; AS, anxiety sensitivity.

A study by $\mathrm{Tsao}$ et $\mathrm{a} \mathrm{l}^{38}$ conducted on 240 children, e.g., found greater AS to be significantly associated not only with current pain but also with somatization. Other studies have also reported high levels of pain-related AS in individuals with depressive disorder, which shows an equally strong clinical overlap with CWP. ${ }^{39}$ A recent twin study conducted by our research group even suggests a shared genetic basis, and hence common etiology, to CWP and depression. ${ }^{20}$ Whether the higher rates of depression and AS in our third somatizing CWP group are a promoter or the consequence of somatic co-symptoms has to be further explored in future studies of different design. 
A second noteworthy finding is that CWP subgroup 3 reporting more co-symptomatology also scored highest in emotional instability. Many of the previous studies investigating how affect and emotional processing influence the experience of pain have focused on the role of negative affect and CWP-related symptoms, including increased perception of pain intensity and chronic fatigue. ${ }^{22,40,41}$ In a large twin study, e.g., Kato et al found emotional instability to be a premorbid predictor of chronic fatigue, with shared genetic mechanisms underlying the expression of the disorder. It is therefore likely that emotional regulation and its correlates (such as emotional instability) are linked to CWP as well. In the twin study by our research group, we also found a strong link between emotional instability, CWP, and depression, highlighting further the complex multifactorial pathogenesis of pain. ${ }^{20}$ In accordance with these previous findings, individuals with more co-symptoms reported greater emotional instability and a lower ability to remain calm when under stress and to react with less aggressive and volatile behavior.

Interestingly, none of the groups differed in any of the behavioral coping strategies. In other words, the behavioral and psychological strategies that individuals employ to master and minimize stressful events, or in this specific case to cope with chronic pain, appeared uninfluenced by the amount and severity of co-symptomatology. This finding is somewhat surprising as a number of studies have suggested a link between adaptive and maladaptive coping strategies and adjustment in chronic pain patients. ${ }^{11,14,42}$ According to our results, however, there seems to be no relationship between the specific strategy applied to cope with pain and potential additional somatization. It is possible that the effects of coping were moderated or mediated by our other variables, such as personality that would mask the effects of adaptive vs. maladaptive coping strategies. It is also plausible that CWP individuals tend to use similar coping strategies, so that the lack of variation within these strategies might explain the fact that no differences could be found within this specific CWP population.

\section{Strengths and limitations}

This study has several potential limitations. First, we relied on questionnaires to diagnose CWP rather than clinical or diagnostic interviews. Thus, our discussion focuses on CWP only on a symptom level and not as a diagnosable disorder. Second, we used a cross-sectional design therefore direction of effect could not be determined. At this stage, it is therefore impossible to say whether the higher rates of depression and anxiety in the high co-symptomatology group are a consequence of the high additional symptom load or whether they represent risk factors for the development of additional somatic symptoms. Third, the results of the LCA are dependent on the items analyzed, and the list was restricted to 12 symptoms.

\section{Conclusion}

Overall, the present findings of three distinct CWP subgroups depending on somatic co-symptoms demonstrate the heterogeneity of CWP. Accurate phenotype description is further crucial for successful research, and more attention should be paid to defining the subgroups within CWP. This will result in targeting therapies better and a stratified approach to patient care. For example, the CWP subgroup with high levels of co-symptoms and anxiety and depression may benefit more than the other subgroups from cognitive behavioral therapy.

\section{Acknowledgments}

$A B$ reports a project grant from the Swisslife Jubilaeumsstiftung. FMW is supported by the EU FP7 project Pain_OMICS and has grant support from Arthritis Research UK (grant number 20682) and the Chronic Disease Research Foundation. TwinsUK is supported by the Wellcome Trust; European Community's Seventh Framework Programme (FP7/20072013). The study also receives support from the National Institute for Health Research (NIHR)-funded BioResource, Clinical Research Facility and Biomedical Research Centre based at Guy's, and St Thomas' NHS Foundation Trust in partnership with King's College London.

\section{Author contributions}

Study concept and design: AB, PH; data collection: FMW; data analyses: $\mathrm{PH}, \mathrm{AB}$; interpretation of data: $\mathrm{AB}, \mathrm{PH}$; manuscript draft: $\mathrm{AB}, \mathrm{PH}, \mathrm{FMW}$; manuscript revision: FMW, PM; approval of final version: AB, PH, FMW, PM. All authors contributed toward data analysis, drafting and critically revising the paper and agree to be accountable for all aspects of the work.

\section{Disclosure}

The authors report no conflicts of interest in this work.

\section{References}

1. McBeth J, Nicholl BI, Cordingley L, Davies KA, Macfarlane GJ. Chronic widespread pain predicts physical inactivity: results from the prospective EPIFUND study. Eur J Pain. 2010;14(9):972-979.

2. Blyth FM. Chronic pain - is it a public health problem? Pain. 2008, 137(3):465-466.

3. Wolfe F, Smythe HA, Yunus MB, et al. The American college of rheumatology 1990 criteria for the classification of fibromyalgia. Report of the multicenter criteria committee. Arthritis Rheum. 1990;33(2):160-172. 
4. Greenspan JD, Craft RM, LeResche L, et al; Consensus Working Group of the Sex, Gender, and Pain SIG of the IASP. Studying sex and gender differences in pain and analgesia: a consensus report. Pain. 2007;132(suppl 1):S26-S45.

5. Hurley RW, Adams MC. Sex, gender, and pain: an overview of a complex field. Anesth Analg. 2008;107(1):309-317.

6. Clauw DJ, Crofford LJ. Chronic widespread pain and fibromyalgia: what we know, and what we need to know. Best Pract Res Clin Rheumatol. 2003;17(4):685-701.

7. Croft PR. The epidemiology of chronic widespread pain. J Musculoskelet Pain. 2002;10(1-2):191-199.

8. Gatchel RJ, Peng YB, Peters ML, Fuchs PN, Turk DC. The biopsychosocial approach to chronic pain: scientific advances and future directions. Psychol Bull. 2007;133(4):581-624.

9. Kato K, Sullivan PF, Pedersen NL. Latent class analysis of functional somatic symptoms in a population-based sample of twins. J Psychosom Res. 2010;68(5):447-453.

10. Mundal I, Gråwe RW, Bjørngaard JH, Linaker OM, Fors EA. Psychosocial factors and risk of chronic widespread pain: an 11-year follow-up study - the HUNT study. Pain. 2014;155(8):1555-1561.

11. Dysvik E, Natvig GK, Eikeland OJ, Lindstrom TC. Coping with chronic pain. Int J Nurs Stud. 2005;42(3):297-305.

12. Poppe C, Crombez G, Devulder J, Hanoulle I, Vogelaers D, Petrovic M. Personality traits in chronic pain patients are associated with low acceptance and catastrophizing about pain. Acta Clin Belg. 2011;66(3):209-215.

13. Smith W, Strachan E, Buchwald D. Coping, self-efficacy and psychiatric history in patients with both chronic widespread pain and chronic fatigue. Gen Hosp Psychiatry. 2009;31(4):347-352.

14. Tan G, Teo I, Anderson KO, Jensen MP. Adaptive versus maladaptive coping and beliefs and their relation to chronic pain adjustment. Clin J Pain. 2011;27(9):769-774.

15. Bair MJ, Robinson RL, Katon W, Kroenke K. Depression and pain comorbidity: a literature review. Arch Intern Med. 2003;163(20):2433-2445.

16. Mahrer NE, Montano Z, Gold JL. Relations between anxiety sensitivity, somatization, and health-related quality of life in children with chronic pain. J Pediatr Psychol. 2012;37(7):808-816.

17. Lahey BB. Public health significance of neuroticism. Am Psychol. 2009;64(4):241-256.

18. Hirsh AT, George SZ, Bialosky JE, Robinson ME. Fear of pain, pain catastrophizing, and acute pain perception: relative prediction and timing of assessment. J Pain. 2008;9(9):806-812.

19. Yunus MB. The role of central sensitization in symptoms beyond muscle pain, and the evaluation of a patient with widespread pain. Best Pract Res Clin Rheumatol. 2007;21(3):481-497.

20. Burri A, Ogata S, Vehof J, Williams F. Chronic widespread pain: clinical comorbidities and psychological correlates. Pain. 2015;156(8):1458-1464.

21. Kato K, Sullivan PF, Evengård B, Pedersen NL. Chronic widespread pain and its comorbidities: a population-based study. Arch Intern Med. 2006;166(15):1649-1654.

22. Bishop MD, Craggs J, Horn ME, Robinson ME, George SZ. Relationship of intersession variation in negative pain related affect and responses to thermally evoked pain. J Pain. 2010;11:172-178.
23. Docampo E, Collado A, Escaramís G, et al. Cluster analysis of clinical data identifies fibromyalgia subgroups. PLoS One. 2013;8(9):e74873.

24. Vincent A, Hoskin TL, Whipple MO, et al. OMERACT-based fibromyalgia symptom subgroups: an exploratory cluster analysis. Arthritis Res Ther. 2014;16(5):463.

25. Spector TD, Williams FM. The UK adult twin registry (TwinsUK). Twin Res Hum Genet. 2006;9(6):899-906.

26. Andrew T, Hart DJ, Snieder H, de Lange M, Spector TD, MacGregor AJ. Are twins and singletons comparable? A study of disease-related and lifestyle characteristics in adult women. Twin Res. 2001;4(6):464-477.

27. Moayyeri A, Hammond CJ, Hart DJ, Spector TD. The UK adult twin registry (TwinsUK resource). Twin Res Hum Genet. 2013;16(1):144-149.

28. White KP, Harth M, Speechley M, Ostbye T. Testing an instrument to screen for fibromyalgia syndrome in general population studies: the London fibromyalgia epidemiology study screening questionnaire. J Rheumatol. 1999;26(4):880-884.

29. Peters MJ, Broer L, Willemen HL, et al. Genome-wide association study meta-analysis of chronic widespread pain: evidence for involvement of the 5p15.2 region. Ann Rheum Dis. 2013;72(3):427-436.

30. Gosling SD, Rentfrow PJ, Swann WB. A very brief measure of the Big-Five personality domains. J Res Pers. 2003;37:504-528.

31. Carver CS, Scheier MF, Weintraub JK. Assessing coping strategies: a theoretically based approach. J Pers Soc Psychol. 1989;56(2):267-283.

32. Peterson RA, Reiss RJ. Anxiety Sensitivity Index Manual. Worthington, $\mathrm{OH}$ : International Diagnostic Systems; 1992.

33. Kessler RC, Ustun TB. The World Mental Health (WMH) survey initiative version of the World Health Organization (WHO) Composite International Diagnostic Interview (CIDI). Int J Methods Psychiatr Res. 2004;13(2):93-121.

34. Muthén LK, Muthén BO. Mplus User's Guide. 7th ed. Los Angeles, CA: Muthén \& Muthén; 2015.

35. Core Team R. R: A Language and Environment for Statistical Computing. Vienna, Austria: R Foundation for Statistical Computing; 2014. Available from: http://www.R-project.org.

36. Asmundson GJ, Vlaeyen JW, Crombez G. Understanding and Treating Fear of Pain. New York: Oxford University Press; 2004.

37. Ocanez KL, McHugh RK, Otto MW. A meta-analytic review of the association between anxiety sensitivity and pain. Depress Anxiety. 2010;27(8):760-767.

38. Tsao J, Allen LB, Evans S, Lu Q, Myers CD, Zeltzer LK. Anxiety sensitivity and catastrophizing: associations with pain and somatization in non-clinical children. J Health Psychol. 2009;14(8):1085-1094.

39. Carleton RN, Abrams MP, Asmundson GJ, Antony MM, McCabe RE. Pain-related anxiety and anxiety sensitivity across anxiety and depressive disorders. J Anxiety Disord. 2009;23(6):791-798.

40. Charlton E. Ethical guidelines for pain research in humans. Committee on ethical issues of the International Association for the Study of Pain. Pain. 1995;63(3):277-278.

41. Kato K, Sullivan PF, Evengård B, Pedersen NL. Premorbid predictors of chronic fatigue. Arch Gen Psychiatry. 2006;63(11):1267-1272.

42. Kohl A, Rief W, Globiewski JA. Acceptance, cognitive restructuring, and distraction as coping strategies for acute pain. J Pain. 2013;14(3): 305-315.
Journal of Pain Research

\section{Publish your work in this journal}

The Journal of Pain Research is an international, peer reviewed, open access, online journal that welcomes laboratory and clinical findings in the fields of pain research and the prevention and management of pain. Original research, reviews, symposium reports, hypothesis formation and commentaries are all considered for publication.

\section{Dovepress}

The manuscript management system is completely online and includes a very quick and fair peer-review system, which is all easy to use. Visit http://www.dovepress.com/testimonials.php to read real quotes from published authors. 